\title{
Basal serum luteinizing hormone value as the screening biomarker in female central precocious puberty
}

\author{
Seung Heo, MD', \\ Young Seok Lee, MD, PhD², \\ Jeesuk Yu, MD, PhD' \\ 'Department of Pediatrics, Dankook \\ University Hospital, Dankook University \\ College of Medicine, Cheonan, Korea \\ ²Department of Diagnostic Radiology, \\ Dankook University Hospital, Dankook \\ University College of Medicine, \\ Cheonan, Korea
}

Purpose: Precocious puberty refers to the development of secondary sex characteristics before ages 8 and 9 years in girls and boys, respectively. Central precocious puberty (CPP) is caused by premature activation of the hypothalamuspituitary-gonadal (HPG) axis and causes thelarche in girls before the age of 8 . A gonadotropin-releasing hormone $(\mathrm{GnRH})$ stimulation test is the standard diagnostic modality for diagnosing CPP. However, the test cannot always be used for screening because it is expensive and time-consuming. This study aimed to find alternative reliable screening parameters to identify HPG axis activation in girls $<8$ years old (CPP) and for girls 8-9 years old (early puberty, EP).

Methods: From January 2013 to June 2015, medical records from 196 girls younger than 9 years old with onset of breast development were reviewed, including 126 girls who had a bone age (BA) 1 year above their chronological age. All patients underwent a GnRH stimulation test, and 117 underwent pelvic sonography. The girls were divided into 4 groups based on age and whether the GnRH stimulation test showed evidence of central puberty. Subanalyses were also conducted within each group based on peak luteinizing hormone (LH) level quartiles.

Results: Basal serum LH level was the most sensitive marker for screening CPP and EP. The cutoff values were $0.245 \mathrm{IU} / \mathrm{L}$ for CPP under 8 years old $(P=0.049$, area under the curve $[A U C]=0.764,88 \%$ sensitivity, $48 \%$ specificity) and $0.275 \mathrm{IU} / \mathrm{L}$ for EP between $8-9$ years old $(P=0.005$, AUC $=0.813,79 \%$ sensitivity, $77 \%$ specificity). Peak $\mathrm{LH}$ level decreased as BMI $z$-score among subgroups increased when there was no difference in $B A$; however, higher BA eliminated this effect.

Conclusion: : Basal serum LH level is a useful screening parameter for diagnosing CPP and EP in girls. Peak LH levels were lower with increasing BMI $z$-score, although older BA eliminated this effect.

Keywords: Central precocious puberty, Thelarche, Luteinizing hormone

\section{Introduction}

Precocious puberty is the development of secondary sex characteristics before ages 8 and 9 years old in girls and boys, respectively. Central precocious puberty (CPP) is caused by premature activation of the hypothalamus-pituitary-gonadal (HPG) axis. In girls, premature thelarche can be the first sign of $\mathrm{CPP}$, and it can be confirmed by the gonadotropin-releasing hormone $(\mathrm{GnRH})$ stimulation test, which detects advancing bone age (BA) or elevated luteinizing hormone ( $\mathrm{LH}$ ) levels. In the United States, CPP is prevalent in approximately 1 in 5,000-10,000, ${ }^{1)}$ however, recent studies have reported an increasing CPP prevalence worldwide. ${ }^{2-4)}$ In addition to endocrine disruptors, improved nutrition and hygiene are thought to contribute to increased CPP incidence. ${ }^{5)}$ Age at menarche and epiphyseal closure can be earlier in patients with CPP, which could result in shortened adult height and adverse psychosocial effects. ${ }^{5-7)}$ Therefore, early CPP diagnosis and treatment are important. 
The GnRH stimulation test is considered the gold standard for diagnosing CPP. However, this test is expensive and timeconsuming to perform. ${ }^{8,9)}$ Many previous studies used basal LH, basal follicle-stimulating hormone (FSH), and ultrasonography for CPP screening, but there are disagreements regarding the appropriate cutoff values. ${ }^{10-16)}$ Therefore, we aimed to identify a reliable screening method for confirming HPG axis activation in girls $<8$ years (CPP) and between 8 and 9 years (early puberty, EP).

\section{Materials and methods}

\section{Subjects}

Initially, 169 girls who visited the Department of Pediatrics, Dankook University Hospital for evaluation of premature thelarche were included. All were $<9$ years old and showed advanced BA over chronological age (CA). They all underwent a GnRH stimulation test between January 2013 and June 2015. Of the 169 patients, 126 had a BA that was more than 1 year above their CA.

None of the girls had hirsutism or other underlying endocrine diseases, congenital anomalies, or organic brain diseases. They also did not have histories of drug ingestion or hormonal therapy prior to testing.

Finally, the 126 children with BA $>1$ year beyond CA were included in the study. The requirement to obtain consent was waived because the study was a retrospective review of anonymized laboratory results and medical data.

\section{Study design}

Patients were classified into 4 groups according to their baseline CA at evaluation and their GnRH stimulation results. Those with a $\mathrm{CA}<8$ years on evaluation were placed into group I, and those with a CA between 8 and 9 years were categorized into group II.

Meanwhile, patients with peak LH levels $\geq 5$ IU/L during GnRH stimulation testing in groups I and II were diagnosed with CPP (group Ia) and EP (group IIa), respectively, and placed in the appropriate pubertal groups (Fig. 1). Those with peak LH level $<5$ IU/L were placed in the non-CPP (group Ib) or non-EP (group IIb) categories, which were the prepubertal groups.

We then categorized pubertal groups (Ia + IIa) into four subgroups according to peak LH quartile, with a peak LH range as follows: subgroup I: 1st quartile (peak LH: 5.05-8.01 IU/L; $\mathrm{n}=22$ ), subgroup II: 2nd quartile (peak LH: 8.06-13.12 IU/L; $\mathrm{n}=22$ ); subgroup III: 3 rd quartile (peak LH: 13.14-23.65 IU/L; $\mathrm{n}=21$ ); and subgroup IV: 4th quartile (peak LH: 23.71-71.00 IU/ $\mathrm{L} ; \mathrm{n}=21$ ).

Medical records were reviewed to collect data on height, weight, body mass index (BMI), and parental height. BA results were determined by hand radiography, and uterine and ovary volumes were determined by pelvic sonography; these results were then reviewed. The serum levels of basal LH, FSH, oestradiol, 17a-hydroxyprogesterone (17-OHP), dehydroepiandrosterone sulfate (DHEA-S), and insulin-like growth factor-1 (IGF1) were also reviewed.

Additionally, CPP and EP patients were classified into 4 subdivided groups according to peak LH quartiles for comparison with BMI $z$-scores and BA.

\section{BA measurement}

To measure BA, a radiograph of the left hand was evaluated by two experienced physicians-pediatric radiologist and a pediatric endocrinologist-who used the Greulich and Pyle method.

\section{GnRH stimulation test}

Blood samples were initially obtained to measure basal serum LH, FSH, and estradiol, and then LH and FSH were measured 30, 45, 60, and 90 minutes after administration of 100 $\mu \mathrm{g}$ of gonadorelin acetate (Relefact; Sanofi-Aventis, Frankfurt, Germany). The highest values were recorded as patients' peak LH and peak FSH values. LH and FSH were measured via immunoradiometric assays (Wallac Wizard 1470 Gamma Counter; GMI, MN, USA), which can evaluate within the following ranges: $0.1-155 \mathrm{IU} / \mathrm{L}$ for $\mathrm{LH}$ and $0.1-129 \mathrm{IU} / \mathrm{L}$ for FSH.

\section{Pelvic sonography}

A total of 117 of the 126 girls underwent transabdominal pelvic sonography with a full bladder using a 5-2-MHz curved probe (iU21, Phillips, The Netherlands), performed by one

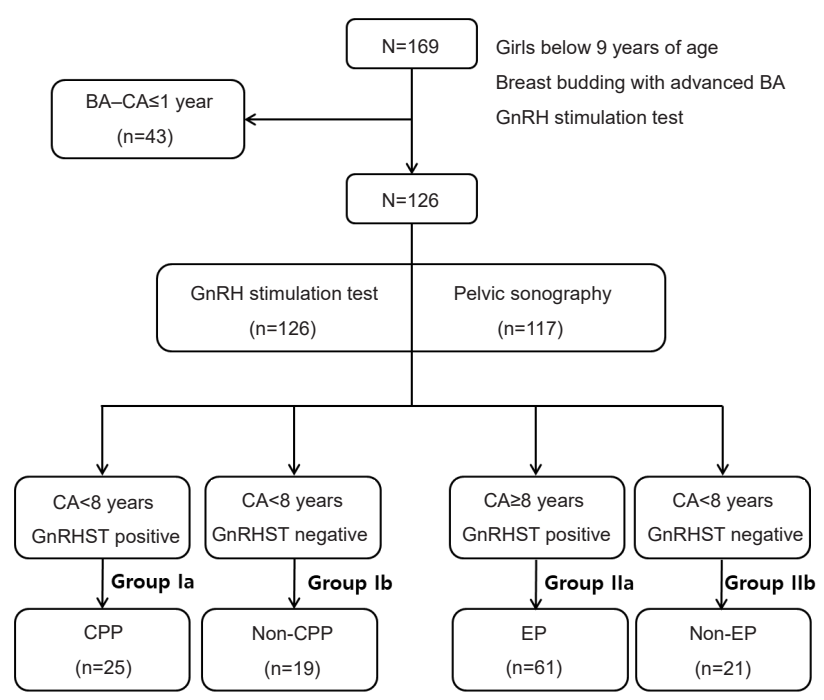

Fig. 1. Study design. BA, bone age; $C A$, chronological age; $G n R H$, gonadotropin-releasing hormone; GnRHST, GnRH stimulation test; CPP, central precocious puberty; EP, early puberty.' 
experienced radiologist. Uterine length was measured from the fundus to the external opening at the maximum length of the midsagittal section in an anteroposterior direction. Ovary volume was estimated using the ellipse formula (length $\times$ height $\times$ transverse diameter $\times 0.5233),{ }^{14)}$ and the side of the ovary was noted.

\section{Statistical analyses}

Results were presented as means \pm standard deviations and with minimum to maximum values. The Mann-Whitney $U$-test was used to compare each parameter between the CPP and non$\mathrm{CPP}$ subjects in group I and between EP and non-EP subjects in group II.

Univariate and stepwise multivariate logistic regression analyses were performed to identify risk factors for CPP and EP and estimate their odds ratios. Receiver operating characteristic (ROC) analysis was used to investigate the predictive capability of basal serum LH and FSH levels. Oneway analysis of variance (ANOVA) was used to compare demographic and clinical parameters of pubertal states between CPP and EP patients according to peak LH quartiles. Post hoc analyses were performed with Tukey test. All statistical analyses were performed using IBM SPSS Statistics ver. 20.0 (IBM Co., Armonk, NY, USA). A $P$-value $<0.05$ was considered significant.

\section{Results}

\section{Patient characteristics}

The clinical and laboratory characteristics of 126 female patients are described in Table 1. Twenty-five (56.8\% of group I)

Table 1. Characteristics of each groups

\begin{tabular}{|c|c|c|c|c|c|c|}
\hline Characteristic & la (CPP) $(n=25)$ & Ib (non-CPP) $(n=19)$ & $P$-value & Ila (EP) $(n=61)$ & Ilb (non-EP) $(n=21)$ & $P$-value \\
\hline \multicolumn{7}{|l|}{ Personal factors } \\
\hline CA (yr) & $7.26 \pm 0.69(5.39-7.93)$ & $7.47 \pm 0.54(6.21-7.99)$ & 0.276 & $8.63 \pm 0.28(8.04-8.98)$ & $8.61 \pm 0.32(8.00-8.99)$ & 0.987 \\
\hline $\mathrm{BMI}$ & $17.21 \pm 2.10(14.00-22.00)$ & $20.09 \pm 3.69(13.70-27.60)$ & $0.010^{*}$ & $18.86 \pm 2.81(15.50-30.00)$ & $19.56 \pm 2.93(15.20-27.30)$ & 0.278 \\
\hline BMI z-score & $0.54 \pm 1.03(-1.30$ to 2.34$)$ & $1.39 \pm 1.29(-1.63-3.10)$ & $0.018^{*}$ & $0.78 \pm 0.88(-0.63-3.22)$ & $1.03 \pm 0.92(-0.80-2.82)$ & 0.258 \\
\hline \multicolumn{7}{|l|}{ Radiologic findings } \\
\hline $\mathrm{BA}(\mathrm{yr})$ & $33 \pm 1.18(6.83-11.50)$ & $9.51 \pm 0.91(7.83-10.50)$ & 0.597 & $10.40 \pm 0.59(9.42-12.00)$ & $10.35 \pm 0.70$ & 0.483 \\
\hline$B A-C A(y r)$ & $2.07 \pm 0.72$ & $2.03 \pm$ & 000 & $1.77 \pm$ & 3.20) & 0.520 \\
\hline \multicolumn{7}{|l|}{ Pelvic sonography } \\
\hline Uterine length $(\mathrm{cm})$ & $\begin{array}{c}3.35 \pm 0.62(2.07-4.89) \\
(n=24)\end{array}$ & $\begin{array}{c}3.63 \pm 0.77(2.42-5.32) \\
(n=18)\end{array}$ & 0.297 & $\begin{array}{c}3.90 \pm 0.83(2.55-7.78) \\
(n=54)\end{array}$ & $\begin{array}{c}3.80 \pm 0.68(2.70-5.27) \\
(n=18)\end{array}$ & 0.760 \\
\hline volume (mL) & $\begin{array}{r}1.72 \pm 1.13(0 \\
(n=2\end{array}$ & $\begin{array}{r}1.44 \pm 0.82( \\
(n=\end{array}$ & 0.438 & $\begin{array}{r}2.29 \pm 1.48 \\
(\mathrm{n}=\end{array}$ & $\begin{array}{r}1.77 \pm 0.7 \\
(\mathrm{n}\end{array}$ & 0.331 \\
\hline Left ovary volume (mL) & $\begin{array}{r}1.42 \pm 0.81(0 . \\
(n=23\end{array}$ & $\begin{array}{r}1.54 \pm 1.19(( \\
(\mathrm{n}=\end{array}$ & 0.775 & $\begin{array}{r}2.01 \pm 1.11 \\
(\mathrm{n}=\end{array}$ & $\begin{array}{r}1.45 \pm 0.64 \\
(n=\end{array}$ & 0.059 \\
\hline volume (mL) & $\begin{array}{c}1.81 \pm 1.11(0.53-4.50) \\
(n=23)\end{array}$ & $\begin{array}{r}1.70 \pm 1.13(( \\
(n=\end{array}$ & 0.674 & $\begin{array}{r}2.48 \pm 1.37 \\
(\mathrm{n}=\end{array}$ & $\begin{array}{r}1.84 \pm 0.68 \\
(n=\end{array}$ & 0.121 \\
\hline \multicolumn{7}{|l|}{ Laboratory findings } \\
\hline$E_{2}(p g / m L)$ & $6.85 \pm 10.33(0.20-41.20)$ & $3.80 \pm 3.13(0.20-12.30)$ & 0.915 & $8.32 \pm 10.72(0.30-57.60)$ & $\begin{array}{c}7.07 \pm 10.39(0.30-47.80) \\
(n=20)\end{array}$ & 0.418 \\
\hline DHEA-S (ug/dL) & $\begin{array}{c}46.00 \pm 41.08 \\
(7.00-169.00)(n=22)\end{array}$ & $\begin{array}{c}63.11 \pm 28.58 \\
(18.00-118.00)(n=18)\end{array}$ & $0.024^{*}$ & $\begin{array}{c}53.61 \pm 25.27 \\
(16.00-113.00)(n=59)\end{array}$ & $\begin{array}{c}68.39 \pm 20.16(40.00- \\
123.00)(n=18)\end{array}$ & $0.012^{*}$ \\
\hline 17-OHP (ng/mL) & $\begin{array}{c}0.96 \pm 0.68(0.22-3.14) \\
(n=23)\end{array}$ & $1.12 \pm 0.64(0.35-3.02)$ & 0.211 & $\begin{array}{c}1.00 \pm 0.66(0.26-3.23) \\
(n=58)\end{array}$ & $\begin{array}{c}0.98 \pm 0.86(0.34-3.35) \\
(n=18)\end{array}$ & 0.344 \\
\hline IGF1 (ng/mL) & $\begin{array}{c}290.85 \pm 78.63 \\
(185.61-435.93)\end{array}$ & $\begin{array}{r}271.57 \pm 8 \\
(139-76-4\end{array}$ & 0.546 & $\begin{array}{c}306.37 \pm 89.66 \\
(157.50-548.03)(n=60)\end{array}$ & $\begin{array}{c}293.14 \pm 66.02(196.54- \\
471.01)(n=20)\end{array}$ & 0.484 \\
\hline Basal LH & $0.86 \pm 0.86(0.06-4.09)$ & $0.34 \pm 0.23(0.11-0.95)$ & $0.003^{*}$ & $1.05 \pm 1.28(0.13-8.16)$ & $0.29 \pm 0.15(0.08-0.71)$ & $0.000^{*}$ \\
\hline Basal FSH (IU/L) & $2.25 \pm 0.98(0.79-4.96)$ & $1.51 \pm 0.88(0.17-3.74)$ & $0.020^{*}$ & $2.62 \pm 1.45(0.50-8.17)$ & $1.52 \pm 0.98(0.48-3.96)$ & $0.000^{*}$ \\
\hline Basal LH/FSH & $0.40 \pm 0.33(0.03-1.43)$ & $0.50 \pm 0.93(0.03+4.00)$ & 0.245 & $0.46 \pm 0.44(0.03-2.32)$ & $0.27 \pm 0.21(0.04-0.90)$ & 0.088 \\
\hline \multicolumn{7}{|l|}{ GnRH stimulation } \\
\hline Peak LH (IU/L) & $13.93 \pm 10.40(5.21-42.28)$ & $3.22 \pm 1.21(0.81-4.99)$ & $0.000^{*}$ & $18.20 \pm 13.40(5.05-71.00)$ & $3.28 \pm 0.84(0.94-4.66)$ & $0.000^{*}$ \\
\hline Peak FSH (IU/L) & $19.45 \pm 6.35(9.98-35.46)$ & $14.89 \pm 6.33(1.10-26.21)$ & $0.045^{*}$ & $15.37 \pm 5.63(5.39-33.11)$ & $12.21 \pm 4.56(3.62-20.35)$ & $0.041^{*}$ \\
\hline Peak LH/FSH & $0.84 \pm 0.75(0.18-2.88)$ & $0.41 \pm 0.78(0.06-3.59)$ & $0.000^{*}$ & $1.33 \pm 0.98(0.20-4.58)$ & $0.33 \pm 0.23(0.15-1.10)$ & $0.000^{*}$ \\
\hline
\end{tabular}

Values are presented as mean \pm standard deviation (range).

Mean comparison between the 2 groups was performed using the Man-Whitney U-test.

CA, Chronological age; BMI, body mass index; BA, bone age; DHEA-S, dehydroepiandrosterone sulfate; 17-OHP, oestradiol,17ahydroxyprogesterone; IGF1, insulin-like growth factor-1; LH, luteinizing hormone; FSH, follicle-stimulating hormone; GnRH, gonadotropinreleasing hormone.

${ }^{*} P<0.05$. 
patients were diagnosed with CPP (group Ia), and 61 (74.3\% of group II) patients had EP (group IIa).

\section{Analysis of basal serum LH and FSH in group I (CPP [la] vs. non-CPP [lb]) and group II (EP [lla] vs. non-EP [Ilb])}

The mean values for weight, BMI $z$-score, DHEA-S, basal $\mathrm{LH}$, basal FSH, peak LH, and peak FSH were significantly different between groups Ia and Ib. BMI $z$-score was lower in group Ia compared to group Ib $(P<0.05)$, whereas DHEA-S was not significantly different in univariate logistic regression analysis (Supplementary Table 1). Stepwise multivariate logistic regression showed that basal LH (odds ratio [OR], 16.236; 95\% confidence interval $[\mathrm{Cl}], 1.014-259.984 ; P=0.049)$ and basal FSH (OR, 2.875; 95\% Cl, 1.083-7.634; $P=0.034)$ are good markers for screening and diagnosing $\mathrm{CPP}(P<0.05)$ (Table 2$)$.

In group II, there were significant differences in the mean values for DHEA-S, basal LH, basal FSH, peak LH, and peak FSH between groups IIa and IIb in univariate regression analyses. By contrast, BA, uterine length, and ovary volumes were not significantly different between the 2 groups (Table 1 ). Stepwise multivariate logistic regression showed that basal LH (OR, 120.848; 95\% Cl, 4.356-3,352.652; $P=0.005)$ and basal FSH (OR, 2.058; 95\% Cl, 1.086-3.901; $P=0.027$ ) were significantly different between groups IIa and IIb (Table 2).

\section{Analysis of basal LH and FSH in the pubertal (la+lla) and prepubertal $(\mathrm{lb}+\mathrm{llb})$ groups}

There were significant differences between group Ia + IIa and group Ib+IIb in terms of BMI, BMI z-score, basal LH, basal FSH, DHEA-S, peak LH, and peak FSH. Univariate logistic regression analyses showed significant differences in larger ovary volume $(P=0.042)$, but the mean values were not significantly different (Supplementary Tables 2 and 3). In stepwise multivariate logistic regression, basal LH (OR, 81.353; 95\% Cl, 6.848-966.476; $P=0.000)$, basal FSH (OR, 1.873; 95\% Cl, 1.019-3.441; $P=0.043$ ), and larger ovary volume (OR, 1.987; 95\% Cl, 1.124-3.513; $P=0.018$ ) were significantly different (Table 3 ).

\section{Decisions for cutoff values}

To evaluate basal LH and FSH as screening parameters for CPP and EP, cutoff values were assessed using ROC curve analysis. Using Youden's index (J), sensitivity, and specificity measures, we selected the best values for screening.

For CPP screening in girls $<8$ years, a basal LH cutoff of 0.245 IU/L yielded an area under the curve (AUC) of $0.764,88 \%$ sensitivity, $48 \%$ specificity, $69 \%$ positive predictive value (PPV), and $75 \%$ negative predictive value (NPV). A basal FSH cutoff value of $1.160 \mathrm{IU} / \mathrm{L}$ had an AUC of $0.706,92 \%$ sensitivity, $43 \%$ specificity, 67\% PPV, and 80\% NPV (Fig. 2A).

For EP screening in girls 8-9 years, a basal LH cutoff value of $\geq 0.275 \mathrm{IU} / \mathrm{L}$ yielded an AUC of $0.813,79 \%$ sensitivity, $77 \%$ specificity, 87\% PPV, and 54\% NPV. Meanwhile, a basal FSH cutoff value of $1.165 \mathrm{IU} / \mathrm{L}$ had an AUC of $0.761,87 \%$ sensitivity, $52 \%$ specificity, $84 \%$ PPV, and 58\% NPV (Fig. 2B).

In girls $<9$ years, for CPP and EP screening, a basal LH cutoff value of $>0.245 \mathrm{IU} / \mathrm{L}$ yielded an AUC of $0.792,88 \%$ sensitivity, $44 \%$ specificity, $77 \% \mathrm{PPV}$, and $63 \% \mathrm{NPV}$, and a basal FSH cutoff value of $\geq 1.165 \mathrm{IU} / \mathrm{L}$ yielded an AUC of $0.763,90 \%$ sensitivity, $50 \%$ specificity, 78\% PPV, and 66\% NPV. A larger ovary cutoff value of $>1.67 \mathrm{~mL}$ yielded an AUC of $0.61162 \%$ sensitivity, $61 \%$ specificity, 77\% PPV, and 40\% NPV.

\section{Analyses according to peak LH quartile in the pubertal group (la+lla)}

The mean values for all variables were compared via 1-way ANOVA across each subgroup (Supplementary Table 4). CA, BMI, BMI $z$-score, BA, uterine length, larger ovary volume, IGF1, and basal LH were significantly different between the subgroups. In Tukey honestly significant difference post hoc

Table 3. Stepwise multivariate logistic analysis of factors associatedwith pubertal response (in GnRH stimulation test)

\begin{tabular}{lcc}
\hline \multirow{2}{*}{ Variable } & \multicolumn{2}{c}{ la+lla vs. Ib+llb } \\
\cline { 2 - 3 } & P-value & Odd ratio $(95 \% \mathrm{Cl})$ \\
\hline $\begin{array}{l}\text { Larger ovary volume } \\
\text { (mL) }\end{array}$ & $0.018^{*}$ & $1.987(1.124-3.513)$ \\
Basal LH (IU/L) & $0.000^{*}$ & $81.353(6.848-966.476)$ \\
Basal FSH (IU/L) & $0.043^{*}$ & $1.873(1.019-3.441)$ \\
\hline
\end{tabular}

Independent variables included BMI Z-score, basal LH, basal FSH, uterine length, dominant ovary, DHEA-S.

$\mathrm{BMI}$, body mass index; LH, luteinizing hormone; $\mathrm{Cl}$, confidence interval; FSH, follicle-stimulating hormone; DHEA-S, dehydroepiandrosterone sulfate.

${ }^{*} P<0.05$.

Table 2. Stepwise multivariate analysis of factors associated with peak LH values

\begin{tabular}{lccccc}
\hline \multirow{2}{*}{ Variable } & \multicolumn{2}{c}{ Group I (la vs. Ib) } & \multicolumn{2}{c}{ Group II (Ila vs. Ilb) } \\
\cline { 2 - 5 } & P-value & Odd ratio $(95 \%$ Cl) & P-value & Odd ratio (95\% Cl) \\
\hline BMI z-score & 0.079 & $0.558(0.291-1.070)$ & & 0.388 & $0.708(0.324-1.549)$ \\
Basal LH (IU/L) & $0.049^{*}$ & $16.236(1.014-259.984)$ & & $0.005^{*}$ & $120.848(4.356-3,352.652)$ \\
Basal FSH (IU/L) & $0.034^{*}$ & $2.875(1.083-7.634)$ & & $0.027^{*}$ & $2.058(1.086-3.901)$ \\
\hline
\end{tabular}

Independent variables included BMI z-score, basal LH, basal FSH, uterine length, DHEA-S.

BMI, body mass index; LH, luteinizing hormone; Cl, confidence interval; FSH, follicle-stimulating hormone; DHEA-S, dehydroepiandrosterone sulfate.

${ }^{*} P<0.05$. 

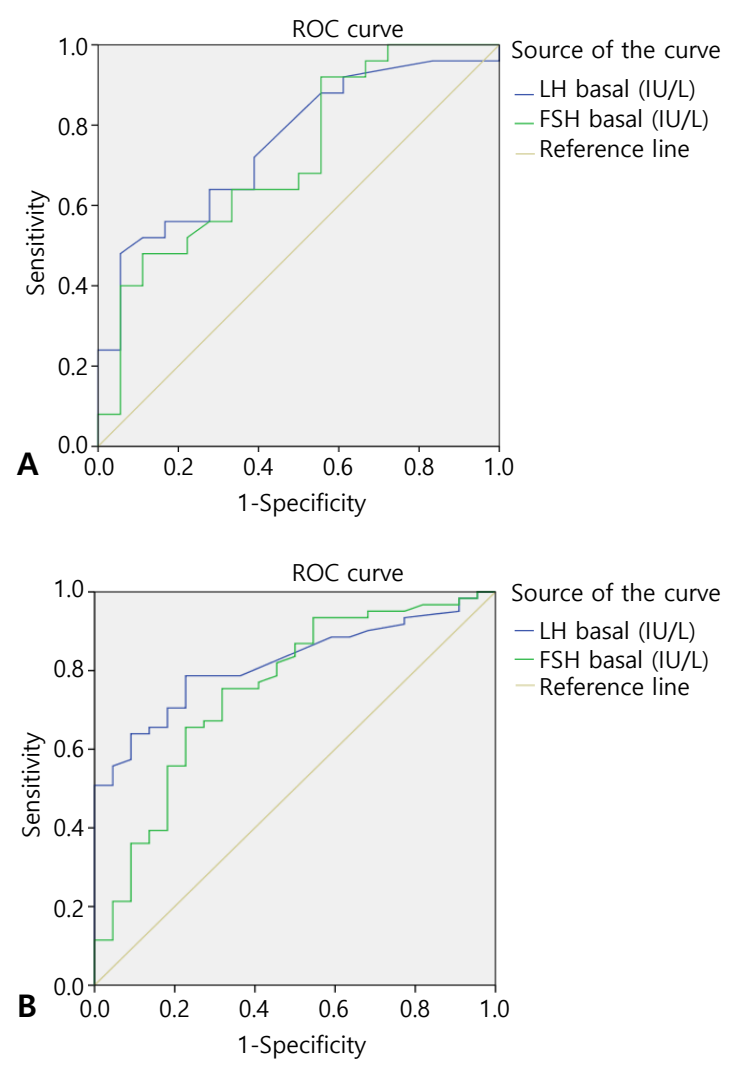

Source of the curve $-\mathrm{LH}$ basal (IU/L) - FSH basal (IU/L) Reference line

\begin{tabular}{llccccc} 
& AUC & Sn (\%) & Sp (\%) & PPV (\%) & NPV (\%) & J \\
\hline Basal LH & 0.813 & & & & & \\
$\geq 0.265$ & & 79 & 71 & 86 & 50 & 0.50 \\
$\geq 0.275$ & & 79 & 77 & 87 & 54 & 0.56 \\
$\geq 0.285$ & & 77 & 77 & 90 & 53 & 0.54 \\
\hline Basal FSH & 0.761 & & & & & \\
$\geq 1.165$ & & 87 & 52 & 84 & 58 & 0.39 \\
$\geq 1.455$ & & 82 & 57 & 85 & 52 & 0.39 \\
$\geq 1.485$ & & 80 & 57 & 86 & 48 & 0.37
\end{tabular}

\begin{tabular}{lcrrrrr} 
& AUC & Sn (\%) & Sp (\%) & PPV (\%) & NPV (\%) & J \\
\hline Basal LH & 0.764 & & & & & \\
$\geq 0.205$ & & 92 & 43 & 68 & 80 & 0.35 \\
$\geq 0.245$ & & 88 & 48 & 69 & 75 & 0.36 \\
$\geq 0.255$ & & 72 & 65 & 72 & 63 & 0.37 \\
\hline Basal FSH & 0.706 & & & & & \\
$\geq 1.025$ & & 92 & 37 & 65 & 81 & 0.29 \\
$\geq 1.160$ & & 92 & 43 & 67 & 80 & 0.34 \\
$\geq 1.330$ & & 88 & 43 & 69 & 78 & 0.31
\end{tabular}

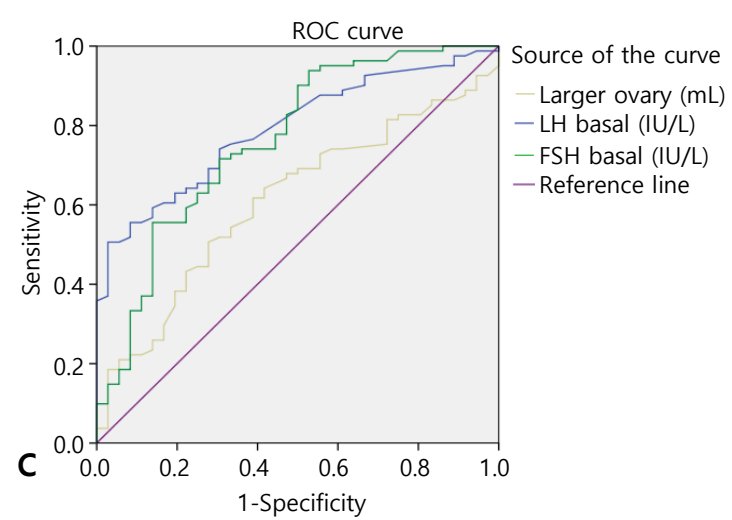

\begin{tabular}{llrrrrr} 
& AC & Sn(\%) & Sp (\%) & PPV (\%) & NPV (\%) & J \\
\hline Basal LH & 0.792 & & & & & \\
$\geq 0.235$ & & 88 & 38 & 75 & 60 & 0.26 \\
$\geq 0.245$ & & 88 & 44 & 77 & 63 & 0.32 \\
$\geq 0.255$ & & 77 & 61 & 81 & 56 & 0.38 \\
\hline Basal FSH & 0.763 & & & & & \\
$\geq 1.165$ & & 90 & 50 & 78 & 66 & 0.40 \\
\hline Larger ovary & 0.611 & & & & & \\
$\geq 1.67$ & & 62 & 61 & 77 & 40 & 0.23
\end{tabular}

Fig. 2. Receiver operating characteristic (ROC) curve and cutoff value for CPP and EP screening. (A) ROC curve for CPP screening of patients $<8$ years. (B) ROC curve for EP screening of patients 8-9 years. (C) ROC curve for CPP+EP screening of patients $<9$ years. CPP, central precocious puberty; EP, early puberty; AUC, area under curve; Sn, sensitivity; Sp, specificity; PPV, positive predictive value; NPV, negative predictive value; J, Youden's index. LH, luteinizing hormone; FSH, follicle-stimulating hormone.

method, mean BMI $z$-score was significantly different between subgroups I and III $(\mathrm{z}=0.74$, standard deviation $[\mathrm{SD}]=0.27$, $P=0.036)$ and between subgroups III and IV $(\mathrm{z}=-0.84, \mathrm{SD}=0.27$, $P=0.014)$ (Fig. 3A). BA was significantly different between subgroups I and IV at 0.77 years $(S D=3.319, P=0.035)$ (Fig. 3B). $\mathrm{BA}-\mathrm{CA}$ was not significantly different between each of the subgroups (Fig. 3C).

\section{Discussion}

Early diagnosis of CPP and EP in girls $<8$ and $8-9$ years, respectively, is important. Random serum basal LH and FSH values are commonly used for early diagnosis of these conditions; however, a clear consensus regarding cutoff values has not been established. We observed that basal LH $>0.1 \mathrm{IU} /$ L had $56.4 \%-94.7 \%$ sensitivity and $64 \%-88.4 \%$ specificity for $\mathrm{CPP}^{12,17,18)}$ The AUC, sensitivity, specificity, PPV, and NPV of 


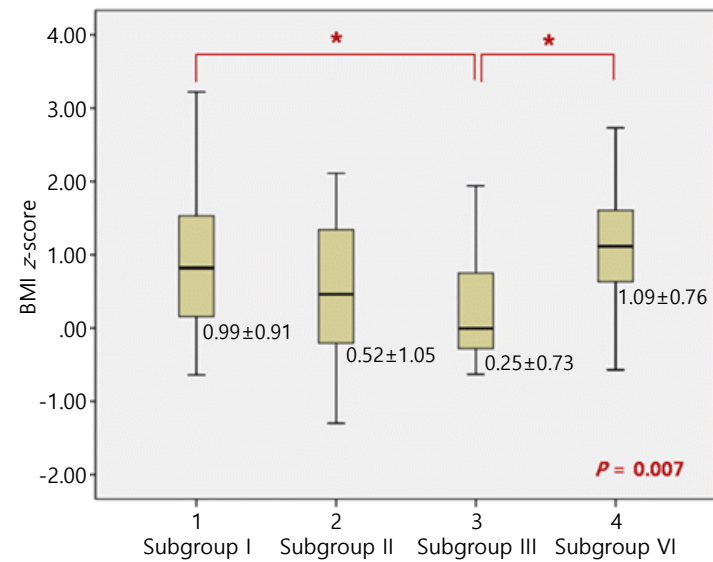

A

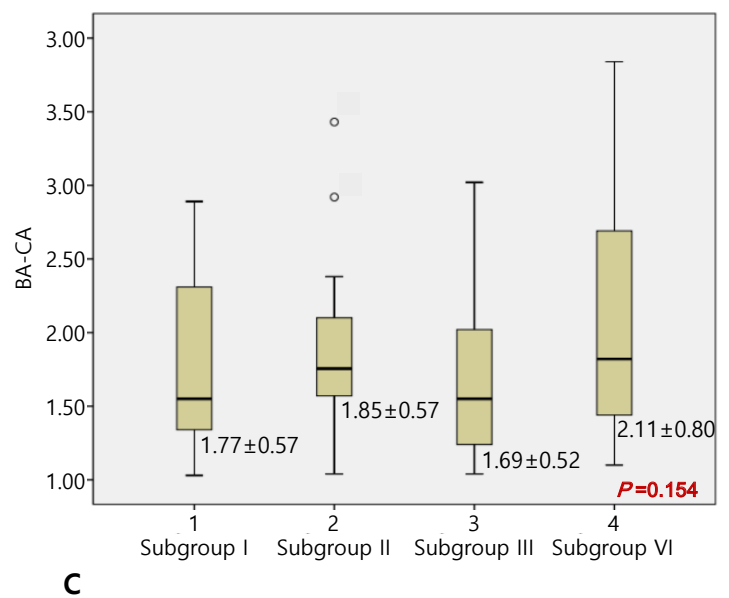

basal LH were similar to those reported in previous studies. Suh et al. ${ }^{19)}$ reported a sensitivity and specificity of $87.8 \%$ and $20.9 \%$, respectively, when the basal LH cutoff value was $>0.22$ IU/L. In our study, the cut-off levels of basal LH for CPP and EP screening were $\geq 0.245 \mathrm{IU} / \mathrm{L}$ and $\geq 0.275 \mathrm{IU} / \mathrm{L}$, respectively (Fig. 2).

Previous studies have also reported that basal FSH can be used for CPP diagnosis. ${ }^{12,13)}$ Pasternak et al. ${ }^{12)}$ reported a sensitivity of $76 \%$ and specificity of $73 \%$ for a basal FSH cutoff of $>2.25 \mathrm{IU} / \mathrm{L}$ for CPP diagnosis. Çatl et al ${ }^{13)}$ reported a sensitivity of $71 \%$ and specificity of $68 \%$ for a cut-off value $>1.9 \mathrm{IU} / \mathrm{L}$ for CPP diagnosis. In our study, we found that basal FSH and LH are effective screening parameters for CPP and $\mathrm{EP}$, respectively, when the cutoff value for basal FSH for CPP screening was $>1.160 \mathrm{IU} / \mathrm{L}$ and the cutoff value for basal FSH for EP screening was $\geq 1.165 \mathrm{IU} / \mathrm{L}$.

Çatl et al ${ }^{13)}$ also reported $100 \%$ sensitivity and $84 \%$ specificity when using peak LH/FSH ratio for CPP diagnosis. Supornsilchai et al. ${ }^{20)}$ reported a sensitivity, specificity, PPV, and NPV of $75 \%, 85 \%, 82 \%$, and $82 \%$, respectively, for CPP diagnosis when the basal LH/FSH ratio cutoff level was $>0.2$, however, the difference in basal and peak LH/FSH levels between the

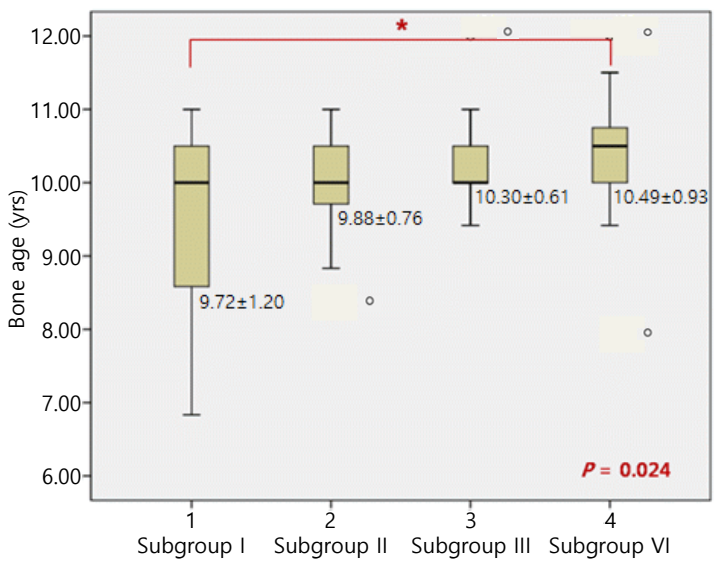

B

Fig. 3. Analyses of pubertal group according to luteinizing hormone peak quartiles. Body mass index (BMI) z-score for each group. (A) BA for each group. (B) $B A-C A$ for each group. BA, bone age; $C A$, chronological age. ${ }^{*} P<0.05$
$\mathrm{CPP}$ and non-CPP groups was not statistically significant in univariate analyses.

Several studies have reported on the usefulness of ultrasound for CPP diagnosis. ${ }^{14-16)}$ Yu et al. ${ }^{14)}$ reported that uterine length, transverse diameter, fundus, volume, and cross-sectional area were significantly larger on ultrasound in CPP patients (uterine length: $2.45 \pm 0.50 \mathrm{~cm}$ vs. $2.63 \pm 0.49 \mathrm{~cm}, P=0.015$; uterine volume: $0.95 \pm 0.62 \mathrm{~cm}^{3}$ vs. $\left.1.35 \pm 0.76 \mathrm{~cm}^{3}, P<0.001\right)$. However, these parameters are not useful for diagnostic purposes because they overlap. In a study by Lee et al., ${ }^{15)}$ the best ultrasound parameter to predict CPP among $192 \mathrm{CPP}$ children $<8$ years was uterine volume at a cutoff value of $3.30 \mathrm{~mL}$, with a sensitivity and specificity of $64.18 \%$ and $71.79 \%$, respectively. Additionally, uterine length (cutoff $=4.09 \mathrm{~cm})$ and ovary volume $($ cutoff $=3.5$ $\mathrm{mL}$ ) have also been reported as useful parameters. De Vries et al. ${ }^{16)}$ reported a sensitivity of $88.8 \%$ and a specificity of $89.4 \%$ for predicting CPP when the uterine volume cut-off was 2.0 $\mathrm{mL}$. Uterine length (cutoff $=3.4 \mathrm{~cm}, 80.2 \%$ sensitivity, $57.8 \%$ specificity) was also a good CPP predictor. In this study, 117 patients underwent pelvic sonography. There was no difference in ovary volume and uterine length between the Ia and Ib groups, nor between the IIa and IIb groups. Moreover, the 
mean values of ovary volume and uterine length were also not significantly different between the Ia+IIa and the Ib+IIb groups. However, univariate and multivariate logistic regression analyses indicated that ovary size was significantly different between the Ia and Ib groups and the IIa and IIb groups, indicating that in addition to basal FSH and LH, a larger ovary can also be used for CPP and EP screening. The cutoff value of larger ovary volume for $\mathrm{CPP}$ and $\mathrm{EP}$ screening was $1.67 \mathrm{~mL}$ with $62 \%$ sensitivity and $61 \%$ specificity.

Higher BMI is associated with a lower LH response to the GnRH stimulation test in boys and girls with $\mathrm{CPP}^{21,22)}$ In this study, the Ia and IIa groups were divided into four subgroups according to peak LH quartile, and each subgroup was compared and analyzed. CA, BA, uterine length, IGF1, and basal LH levels increased proportionally with peak LH, indicating that the pubertal process progresses with increasing age. Larger ovary volumes tended to be proportional to peak $\mathrm{LH}$, although the mean values in subgroup II were smaller than those in subgroup I without a statistically significant difference in post hoc analysis.

Among CPP children, studies of GnRH-stimulation tests for early pubertal stages showed a lower LH response with higher BMI but no response association was observed as pubertal stage increased. ${ }^{21,23)}$ In this study, BMI and BMI $z$-score tended to be lower in subgroups I, II, and III when peak LH was higher, but the BMI $z$-score was higher in subgroup IV, which had the highest peak LH. BMI $z$-score was significantly different $(P=0.007)$ according to ANOVA results for subgroups I and III, although BA was not different (Fig. 3A, B). Mean BMI $z$-scores were significantly different between subgroups I and III and between subgroups III and IV, suggesting that peak LH response was weaker in the presence of higher BMI $z$-scores when BA was not significantly different. In subgroup IV, BA was significantly higher than in subgroup I and peak LH levels also showed higher values than subgroup I, suggesting that increased BA eliminates the lower $\mathrm{LH}$ response during a GnRH stimulation test in the presence of increased BMI z-score. BACA was not different among the subgroups (Fig. 3C).

A limitation of this study is that it was performed at a singlecenter and included a small number of patients.

In conclusion, we found that basal serum LH, basal serum FSH, and larger ovary volume can be used for CPP and EP screening. In particular, random basal LH values are useful for CPP screening among girls $<8$ years and for EP screening among girls $8-9$ years. The cutoff values of basal serum LH are 0.245 IU/L for CPP and 0.275 IU/L for EP. Additionally, basal serum FSH and larger ovary volume on ultrasonography may also be useful screening parameters for CPP and EP. Moreover, we also found that as BMI $z$-score increases, peak LH response was reduced in EP stages, although higher BA eliminates the effect. However, the extent to which BA impacts this phenomenon is unclear, and further studies are needed. Given that peak LH value on GnRH stimulation tests is masked by higher BMI, GnRH stimulation test results should be interpreted cautiously in obese patients.

\section{Ethical statement}

This study was approved by the Institutional Review Board of Dankook University Hospital (DKUH 2016-10-006).

\section{Conflict of interest}

No potential conflict of interest relevant to this article was reported.

\section{Supplementary materials}

Supplementary Tables 1-4 can be found via http://doi. org/10.6065/apem.2019.24.3.164.

\section{References}

1. Partsch CJ, Sippell WG. Pathogenesis and epidemiology of precocious puberty. Effects of exogenous oestrogens. Hum Reprod Update 2001;7:292-302.

2. Teilmann G, Pedersen CB, Jensen TK, Skakkebaek NE, Juul A. Prevalence and incidence of precocious pubertal development in Denmark: an epidemiologic study based on national registries. Pediatrics 2005;116:1323-8.

3. Sørensen K, Mouritsen A, Aksglaede L, Hagen CP, Mogensen SS, Juul A. Recent secular trends in pubertal timing: implications for evaluation and diagnosis of precocious puberty. Horm Res Paediatr 2012;77:137-45.

4. Aksglaede L, Sørensen K, Petersen JH, Skakkebaek NE, Juul A. Recent decline in age at breast development: the Copenhagen Puberty Study. Pediatrics 2009;123:e932-9.

5. Willemsen RH, Elleri D, Williams RM, Ong KK, Dunger DB. Pros and cons of GnRHa treatment for early puberty in girls. Nat Rev Endocrinol 2014;10:352-63.

6. Lakshman R, Forouhi NG, Sharp SJ, Luben R, Bingham SA, Khaw KT, et al. Early age at menarche associated with cardiovascular disease and mortality. J Clin Endocrinol Metab 2009;94:4953-60.

7. Prentice P, Viner RM. Pubertal timing and adult obesity and cardiometabolic risk in women and men: a systematic review and meta-analysis. Int J Obes (Lond) 2013;37:103643.

8. Pescovitz OH, Hench KD, Barnes KM, Loriaux DL, Cutler GB Jr. Premature thelarche and central precocious puberty: the relationship between clinical presentation and the gonadotropin response to luteinizing hormone-releasing hormone. J Clin Endocrinol Metab 1988;67:474-9.

9. Kim HK, Kee SJ, Seo JY, Yang EM, Chae HJ, Kim CJ. Gonadotropin-releasing hormone stimulation test for precocious puberty. Korean J Lab Med 2011;31:244-9.

10. Lee DS, Ryoo NY, Lee SH, Kim S, Kim JH. Basal luteinizing hormone and follicular stimulating hormone: is it sufficient for the diagnosis of precocious puberty in girls? Ann Pediatr Endocrinol Metab 2013;18:196-201. 
11. Lee HS, Park HK, Ko JH, Kim YJ, Hwang JS. Utility of Basal luteinizing hormone levels for detecting central precocious puberty in girls. Horm Metab Res 2012;44:851-4.

12. Pasternak Y, Friger M, Loewenthal N, Haim A, Hershkovitz E. The utility of basal serum LH in prediction of central precocious puberty in girls. Eur J Endocrinol 2012;166:2959.

13. Çatlı G, Erdem P, Anık A, Abacı A, Böber E. Clinical and laboratory findings in the differential diagnosis of central precocious puberty and premature thelarche. Turk Pediatri Ars 2015;50:20-6.

14. Yu J, Shin HY, Lee SH, Kim YS, Kim JH. Usefulness of pelvic ultrasonography for the diagnosis of central precocious puberty in girls. Korean J Pediatr 2015;58:294-300.

15. Lee SH, Joo EY, Lee JE, Jun YH, Kim MY. The diagnostic value of pelvic ultrasound in girls with central precocious puberty. Chonnam Med J 2016;52:70-4.

16. de Vries L, Horev G, Schwartz M, Phillip M. Ultrasonographic and clinical parameters for early differentiation between precocious puberty and premature thelarche. Eur J Endocrinol 2006;154:891-8.

17. Neely EK, Wilson DM, Lee PA, Stene M, Hintz RL. Spontaneous serum gonadotropin concentrations in the evaluation of precocious puberty. J Pediatr 1995;127:47-52.
18. Lee PA. Laboratory monitoring of children with precocious puberty. Arch Pediatr Adolesc Med 1994;148:369-76.

19. Suh J, Choi MH, Kwon AR, Kim YJ, Jeong JW, Ahn JM, et al. Factors that predict a positive response on gonadotropinreleasing hormone stimulation test for diagnosing central precocious puberty in girls. Ann Pediatr Endocrinol Metab 2013;18:202-7.

20. Supornsilchai V, Hiranrat P, Wacharasindhu S, Srivuthana $S$, Aroonparkmongkol S. Basal luteinizing hormone/ follicle stimulating hormone ratio in diagnosis of central precocious puberty. J Med Assoc Thai 2003;86 Suppl 2:S145-51.

21. Fu JF, Liang JF, Zhou XL, Prasad HC, Jin JH, Dong GP, et al. Impact of BMI on gonadorelin-stimulated LH peak in premenarcheal girls with idiopathic central precocious puberty. Obesity (Silver Spring) 2015;23:637-43.

22. Lee HS, Park HK, Ko JH, Kim YJ, Hwang JS. Impact of body mass index on luteinizing hormone secretion in gonadotropin-releasing hormone stimulation tests of boys experiencing precocious puberty. Neuroendocrinology 2013;97:225-31.

23. Lee HS, Yoon JS, Hwang JS. Luteinizing hormone secretion during gonadotropin-releasing hormone stimulation tests in obese girls with central precocious puberty. J Clin Res Pediatr Endocrinol 2016;8:392-8. 